\title{
Instagram Stories versus Facebook Wall: an advertising effectiveness analysis
}

Instagram Stories versus Facebook Wall

\section{Instagram Stories versus Facebook Wall: un análisis de la efectividad publicitaria}

\author{
Daniel Belanche, Isabel Cenjor and Alfredo Pérez-Rueda \\ Department of Marketing and Market Research, Faculty of Economics and \\ Business Studies, University of Zaragoza, Zaragoza, Spain
}

\begin{abstract}
Purpose - This paper aims to investigate advertising effectiveness in Instagram and Facebook, the two most important social media platforms. It helps to understand which should be chosen depending on the target audience of the campaign.

Design/methodology/approach - The study examines advertising effectiveness in these social media in terms of ad attitude, ad intrusiveness and loyalty intentions. An online survey was conducted with 303 social media users. Age and gender are proposed as moderators.

Findings - The results indicate that Instagram Stories not only enhances consumer attitude toward ads but also increases perceived intrusiveness, compared to Facebook Wall. Millennials are more disturbed by Facebook Wall ads than non-millennial users. A triple interaction effect reveals that non-millennial men are more loyal toward Facebook Wall ads, whereas millennials of both genders and non-millennial women are more loyal to ads on Instagram Stories.

Practical implications - Advertisers should be aware of the differential features and segmentation possibilities in social media to better address their target audiences. More precisely, the research findings suggest that professionals should focus on Instagram Stories when targeting millennials and non-millennial women, and on Facebook Wall when targeting non-millennial men.

Originality/value - This study is one of the first to contribute to the literature on Instagram Stories as an advertising platform and compare its differential features with those of more established social media, such as Facebook Wall.
\end{abstract}

Keywords Ad effectiveness, Attitude toward the ad, Intrusiveness, Loyalty, Instagram Stories, Facebook Paper type Research paper

(C) Daniel Belanche, Isabel Cenjor and Alfredo Pérez Rueda. Published in Spanish Journal of Marketing - ESIC. Published by Emerald Publishing Limited. This article is published under the Creative Commons Attribution (CC BY 4.0) licence. Anyone may reproduce, distribute, translate and create derivative works of this article (for both commercial and non-commercial purposes), subject to full attribution to the original publication and authors. The full terms of this licence maybe seen at http://creativecommons.org/licences/by/4.0/legalcode

This work was supported by Gobierno de Aragón S20_17R, Ministerio de Economía y Competitividad ECO2019-76768-R, and Obra Social Ibercaja - Universidad de Zaragoza JIUZ-2017-SOC-05.

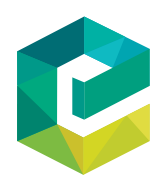

Spanish Journal of Marketing Vol. 23 No. 1, 2019 pp. 69-94 2444-9709 DOI 10.1108/SJME-09-2018-0042 


\section{Resumen}

Propósito de la investigación - Esta investigación compara la efectividad publicitaria en Instagram y Facebook en función del público objetivo.

Metodología y diseño - La investigación analiza las diferencias entre cada formato de red social en términos de actitud hacia el anuncio, intrusividad percibida y lealtad hacia el producto o marca anunciado. Mediante una encuesta online a 303 consumidores, se proponen efectos directos y efectos moderación de la edad y el género.

Recomendaciones - Los resultados indican que Instagram Stories mejora la actitud hacía el anuncio, pero aumenta también la intrusividad en comparación con Facebook Wall. La publicidad en Facebook Wall es más intrusiva para los millennials que para los no-millennials. Instagram Stories incrementa la lealtad entre los usuarios millennial de ambos sexos y las mujeres no-millennial; en cambio, los hombres no-millennial son más leales a la publicidad en Facebook Wall.

Implicaciones prácticas - Los anunciantes deben aprovechar los nuevos formatos y las posibilidades de segmentación que les brindan las redes sociales para llegar a su público objetivo de manera más efectiva. Concretamente, los hallazgos de la investigación sugieren que deberían centrarse en Instagram Stories para dirigirse a un público millennial y a mujeres no-millennial; y en Facebook Wall, cuando su público objetivo sean los hombres no-millennial.

Originalidad - Este estudio es uno de los primeros que aborda el uso de Instagram Stories como soporte publicitario y lo compara con formatos publicitarios consolidados como Facebook Wall.

Palabras clave - Efectividad publicitaria, Actitud hacia el anuncio, intrusividad, lealtad, Instagram Stories, Facebook

Tipo de artículo - Trabajo de investigación

\section{Introduction}

Because every media source is almost saturated by advertising messages, firms try to find new ways to address their public. This is the case with social media advertising, which is growing at over 20 per cent every year (Marinucci, 2018). Social media have proven to be interactive channels full of possibilities for enhanced audiovisual presentation of products and services, increasing users' control of their advertising experiences and offering more attractive and sophisticated forms of digital advertising than traditional mass media (Li and Lo, 2015; Pashkevich et al., 2012).

Instagram Stories, launched in August 2016, is probably the most salient and innovative recent social media development. Stories is an Instagram feature, which operates also on other platforms, such as Snapchat, that allows users to upload ephemeral contents (photos, short videos and live stream transmission), which remain on the network for only $24 \mathrm{~h}$. In terms of design and appearance, and distinct from most social media walls, where users have to scroll down, Stories are presented on the whole screen for $15 \mathrm{~s}$. Each story (i.e. message, video, picture or image featured, with animated effects) is followed by another story, and the user has the control to go back and forth to the previous and next stories in a time-sequenced order. In turn, advertisers present their ads within the Stories feature, that is, as an additional story with the same design as the stories created by users, but labeled as "advertising" on the top left of the screen. As is usual in other social media ad formats, the advertised content allows users to click on it to access more information on a brand profile, the information search being an important part of the shopping decision process (Flavián et al., 2009).

The differential features of innovative advertising formats, such as Instagram Stories, might enhance the success of a social media advertising campaign. Nevertheless, novel advertising with improved interactive options will not be useful for advertisers if the format is unable to attract consumers and to provide greater advertising effectiveness than alternative social media advertising formats (Belanche et al., 2017a; Tan et al., 2018). In such multifaceted advertising ecosystems, advertisers need to choose between the different social 
media to place advertising campaigns effectively and efficiently (Pikas and Sorrentino, 2014). Faced with the need to invest limited budgets in social media platforms in the absence of a clear criterion, advertising professionals need guidance to make their investment choices. As an additional element to be considered, each advertising campaign has concrete objectives based on reaching a specific target audience (e.g. in terms of age or gender), that will be best achieved by placing the ads on the appropriate social media.

Previous literature has focused on Facebook as the prototypical leading social medium and found that ads on that platform enhance brand image and brand equity by leveraging eWOM (Dehghani and Tumer, 2015), but it also raises intrusiveness concerns (Lin and Kim, 2016). In turn, recent research shows that newer social media platforms, such as Snapchat or Instagram, are powerful tools for increasing brand reputation and for reaching younger audiences (Sashittal et al., 2016; Barry et al., 2016). However, the scant research comparing advertising across social media platforms does not consider the distinctive features of the newer social media formats (Pikas and Sorrentino, 2014), it focuses exclusively on enhancing consumer engagement on social media (Ashley and Tuten, 2015; Voorveld et al., 2018), and does not compare specific measures of advertising effectiveness across platforms.

Given both the importance of examining the growing social media format of Instagram Stories as a marketing tool, and the need to evaluate its advertising effectiveness compared to established social media platforms or formats, there is an urgent need to investigate this research gap. Thus, considering the existing opportunities for the management of online advertising campaigns, our research contributes to a better understanding of current social media formats. Specifically, this study helps to provide answers to basic questions for advertisers, such as which social media should be chosen to increase the effectiveness of an advertising campaign, or whether this effectiveness depends on the characteristics of the target audience.

To address these issues, and taking account of previous research on online advertising (Ljepava et al., 2013; Phua et al., 2017; Sheldon and Bryant, 2016), this work compares advertising effectiveness between the two most popular social media platforms, Instagram Stories and Facebook Wall. On the one hand, Facebook is a paradigmatic social network which continues to be the number one social platform, with 2,200 million active users monthly (Kallas, 2018), and an advertising revenue of 6,820 million (US\$), increasing by 59 per cent since 2015 (Leibowitz, 2018). On the other hand, Instagram is the social media with the greatest growth in Western countries, such as Spain (Constine, 2018), with more than 800 million active users worldwide, and more than 1 million advertisers (Leibowitz, 2018). Instagram is not only one of the fastest-growing social media, but is a social virtual space where individuals like to spend time (Sheldon and Bryant, 2016); visitors stay 45 per cent longer than on Facebook, and 40 per cent longer than on Twitter (Alter, 2018). The incredible growth of Instagram, and particularly the recent launching of Instagram Stories, demands that researchers analyze its differential features and to compare its value for advertisers to that of well-established social media formats, such as Facebook Wall. Based on reactance theory (Brehm, 1966), our research assumes there is a difference between users' perceptions and reactions toward stationary advertising social media formats, such as Facebook Wall, and more dynamic social media formats, such as in Instagram Stories, that affects advertising effectiveness (i.e. attitude toward the ad, reduced intrusiveness and loyalty). Based on previous knowledge such as the reactance theory (Brehm, 1966), we propose that users may have a higher motivation to process ephemeral contents that allow them to freely interact with the ad, as it is the case of Instagram Stories, in contrast to static formats such as Facebook Wall that restrict the incorporation of interactive features. In addition, to better understand the phenomenon, we include Instagram Wall as a control group to assess to what extent any differences are due to type of social media or to type of format[1]. 
SJME

23,1

This research also aims to understand how advertising effectiveness can be improved depending on the social media platform and the target audience. Both classic advertising research and recent social media studies suggest that fundamental personal factors, such as age and gender, alter commercial information processing (Alalwan et al., 2017; Katz et al.1974). Thus, we contribute to the understanding of new social media use by consumers based on their sociodemographic profiles and its important advertising segmentation possibilities. In doing so, we analyze to what extent advertising effectiveness in each medium is moderated by the two most important demographic variables - age and gender.

\section{Literature review}

The internet has changed the advertising industry. Indeed, digital platforms, involving browsers, Webpages and social media advertising have confronted the hegemonic role of television, radio and newspapers in advertising. Recent studies estimate that the percentage of advertising investment assigned to online channels will represent 44 per cent of all global advertising spending in 2018, and 50 per cent in 2020 (Handley, 2017).

The transition from traditional advertising to online channels has been motivated by consumers' preference for digital media. Internet characteristics, such as ubiquity and immediacy, and the evolution of technological devices (e.g. smartphones) have transformed consumer habits and fostered new forms of interaction with other users, firms and content creators (Hussain and Lasage, 2014; Flavián et al., 2012.). More than 3,196 million people worldwide use social media today, a number which is growing at 13 per cent every year (Cooper, 2018). The increasing use of social media to access information and entertainment helps comprehend how much information and communication technology is affecting users' everyday lives. Social media platforms are used to connect with friends and brands (Rambe and Retumetse, 2017) and influencers (Casaló et al., 2018), and to access information about current news (Allcott and Gentzkow, 2017) and events (Grömping and Sinpeng, 2018). People spend more time on social media than watching television; on average, 50 per cent of the planet's population use Facebook daily, while only 39 per cent watch television (Cooper, 2018). In addition, four of every ten internet users say they follow their favorite brands on social media (GlobalIndex, 2018). However, users' concerns about the lack of privacy in social media (Jung, 2017), and about the inappropriate use of their data for commercial purposes (Allcott and Gentzkow, 2017), are challenging perceptions of social media, which suggests that advertisers should be careful in selecting the social media and formats to place their campaigns.

Hence, social media have altered marketing communications by shifting the ways in which consumers select, share and appraise information (Sheldon and Bryant, 2016). In other words, social media is emerging as a major advertising vehicle in modern society (Jung, 2017). Indeed, these networking platforms base their business models on online advertising (Belanche et al., 2017b); it is a prosperous business that increases its revenues over 20 per cent annually (Marinucci, 2018). From this developing digital environment based on advertising income, a wide universe of opportunities emerges to increase ad effectiveness. Indeed, social media today play a key role in determining advertising effectiveness; these platforms are now considered the main source of information during the purchase decision-making process (Hamilton et al., 2016; Zhu et al., 2016; Erkan and Evans, 2016). Nevertheless, social media advertising is also criticized for the increasing annoyance it causes users during navigation (Voorveld et al., 2018). Several recent studies suggest that consumer perceptions of online advertising are becoming increasingly negative, certain formats being considered intrusive by consumers (Chatterjee, 2008; Rotfeld, 2006; Truong and Simmons, 2010). In addition, advertisers often believe that some social media ads are ineffective, and that constantly surrounding consumers by a wide quantity of intrusive 
commercial information does not guarantee their attention (Pikas and Sorrentino, 2014). For example, recent research found that students do not pay much attention to Facebook advertisements (Rambe and Retumetse, 2017). Thus, there is a need to better understand consumers' perceptions of ads on the various social media formats to help managers choose the most effective in advertising terms.

\subsection{Ad effectiveness}

Advertising effectiveness has been a goal for advertisers and a topic of research interest among advertising scholars in the past decades (Danaher, 2017). Previous literature in this field has found that consumers' attitudes toward an ad, intrusiveness and loyalty are the three key variables related to advertising effectiveness in the digital context (Ashley and Tuten, 2015; Goodrich et al., 2015; Belanche et al., 2017a).

Attitude is the main driver of consumer volitional behavior (Eagly and Chaiken, 1993). Thus, in a communication setting, attitude toward an ad is one of the best indicators of ad effectiveness (Goldsmith et al., 2000). Attitude toward the ad has been defined as "a predisposition to respond in a favorable or unfavorable manner to a particular advertising stimulus during a particular exposure occasion" (Lutz, 1985; p. 53). According to the literature on persuasion, generating favorable attitudes towards an ad is fundamental to make consumers, at least, consider the advertised products and services. Thus, creating a favorable predisposition in the viewer toward an ad may be crucial for attracting and engaging consumers (Bright and Daugherty, 2012).

Ad intrusiveness is defined as "the degree to which advertisements in a media vehicle interrupt the flow of an editorial unit" (Ha, 1996; p. 77). More specifically, the Internet is a goaloriented medium where advertisements can be perceived by users as more intrusive than in other media (Cho and Cheon, 2004). Thus, perceptions of intrusiveness might be categorized as a negative marketing consequence linked to users' irritation and brand avoidance but may also increase the likelihood of abandoning the online platform (Goodrich et al., 2015).

Finally, marketers' are focusing their efforts in digital advertising on increasing campaign persuasiveness to increase consumers' loyalty to their brands and products (Van Noort et al., 2012). Previous literature on advertising persuasiveness proposes purchase intention and positive word-of-mouth communication (WOM) as the main indicators of consumer loyalty (Aydin and Özer, 2005; Chi and Qu, 2008; Cronin et al., 2000; Gruen et al., 2006). The consumer journey, which starts with the recognition of the need, finishes with the purchase decision and post-purchase activities (Puccinelli et al., 2009; Yadav et al., 2013). Thus, intention to purchase is an important indicator of the persuasive effectiveness of social media in terms of loyalty (Dehghani and Tumer, 2015). An additional sign of loyalty traditionally researched by advertising scholars is the intention to engage in positive wordof-mouth (WOM) (Chen et al., 2014; Chu and Kim, 2018); loyal consumers tend to recommend the brand to motivate subsequent purchase decisions by other consumers (De Bruyn and Lilien, 2008; Lopez and Sicilia, 2014).

\subsection{Development of hypotheses}

Following previous studies (Auschaitrakul and Mukherjee, 2017), our research proposes that each platform and its associated features act as contextual factors influencing consumers' perceptions of, and intentions toward, the ads presented during navigation. In other words, social media may affect advertising persuasiveness because the navigating experience (i.e. distinctive features) on each media can exert an influence on the consumer's susceptibility to be persuaded.

2.2.1 The influence of social media platforms. Instagram started as a social media platform where users could edit photographs and short videos with filters to share on 
their profiles. Compared to Facebook, which is more focused on information exchange and networking (Sheldon and Bryant, 2016), Instagram is more focused on personal self-promotion (Marcus, 2015) and enjoyment (Casaló et al., 2017a) in the social domain. Instagram makes it possible to have ephemeral relationships in a highly user-controlled environment (Sheldon and Bryant, 2016) where users promote themselves as personal brands. Expanding this approach, Instagram has implemented a wide range of personalization characteristics which reinforce the already existing relation between Instagram and narcissism (Buffardi and Campbell, 2008). Unlike Facebook, where advertiser content is presented in a more static and reduced space, the ads in Instagram Stories often mimic the users' input in the use of whole screen records, tags and animated features. These two Instagram Stories trends (i.e. users employing their profiles to "advertise" their own personal brand, advertisers allowed to create more dynamic ads in a similar vein to the lively content created by users), together with the notion of immediacy and closeness of the stories, may increase perceptions of brand familiarity and favorability, and diminish the intrusiveness perception of ads presented on this media (Kim and Johnson, 2016). Furthermore, as an additional sign of how advertising is integrated into this medium, the same story used as content for followers might be used as an ad for non-followers. Thus, on the assumption that Instagram aims to be a platform useful for both personal and commercial brand promotion, users might be prone to process ads on the media more favorably than in other platforms.

Alternatively, the notion of time and its ephemeral contents are other important elements of Instagram Stories, which differ from the stable and always accessible contents in Facebook. Instagram Stories are designed around the concept of "sharing a moment" during a limited period, on just one day. This feature requires users to check their Instagram mobile apps frequently to ensure they view the content uploaded by the profiles they follow. This may motivate the viewers to process rapidly the basic elements of a story to check whether they are interested in the content and will continue to view the whole piece (Sutherland, 2014). Compared to non-skippable stable ads (such as those appearing in Facebook Wall), more interactive advertising increases the user's motivation to process information and generate favorable evaluations of the ads (Belanche et al., 2017a; Pashkevich et al., 2012). Instagram Stories provides users and advertisers with small pieces of information via $5 \mathrm{~s}$ photo, $15 \mathrm{~s}$ video and live retransmissions that appear between stories. These basic features also help attract the user's attention in an immersive and interactive way that, in turn, enhances persuasion (Vollmers and Mizerski, 1994) and advertising effectiveness (Lombard and SnyderDuch, 2001).

In this vein, psychological reactance theory explains how humans react against rules that are perceived as a loss of freedom (Brehm, 1966). Psychological reactance theory has been used to explain how consumers react negatively to ads that interfere with their cognitive processes (Goodrich et al., 2015; Redondo and Aznar, 2018), especially to online advertising techniques that hinder their control of the advertising experience (Li et al., 2002). In this sense, the innovative features of Instagram Stories increase the user's opportunities to interact with ad content (e.g. skip, stop, go back, follow a hashtag, etc.), a content that is animated and personalized by the advertiser of the brand. This might be perceived by the user as an almost unrestricted interaction with the ad when compared to the less dynamic Facebook Wall ads that may be perceived as intrusive or as threatening the user's freedom during online navigation (Li et al., 2002). Thus, users may develop more favorable perceptions and reactions toward ads on Instagram Stories than to ads on Facebook Wall. 
Consequently, we propose the first hypothesis of the study:

H1. Compared to Facebook Wall, Instagram Stories increases ad effectiveness in terms of (a) ad attitude, (b) (reduced) ad intrusiveness and (c) loyalty.

\section{Instagram Stories versus Facebook Wall}

2.2.2 The moderating effect of age. The number of studies examining age as an essential factor of customer orientation toward commercial activities has increased significantly in the past years (Alalwan et al., 2017; Cornelis and Peter, 2017; Taylor et al., 2011). Following this research stream, we distinguish between millennial and non-millennial users of social media. Although there is no consensus about the specific range, the previous literature tends to consider millennials as born between 1985 and 2000 (Pendergast, 2009; Real et al., 2010). The literature describes millennials as users who are very familiar with online media and other digital aspects of communication and purchase processes (Smith, 2011). Due to technological advancements (Deal et al., 2010), millennials and social media platforms have followed a parallel development; millennials are more accustomed to dealing with short information capsules and interactivity features (i.e. swipe, "I like" buttons, etc.) than older users (Myers and Sadaghiani, 2010). This more interactive learning experience influences how users process online advertising information (Belanche et al., 2017b). According to the limited capacity model of mediated message processing (Lang, 2000), this learned capacity influences the individual's ability to process the information on highly dynamic social media platforms, which leads to more positive attitudes. In addition, there is also evidence that information processing capacity reduces with age (Phillips and Sternthal, 1977), which suggests that older users will have more difficulty in processing highly dynamic content (i.e. Instagram Stories) than millennials. Following overload theory (Malhotra, 1982), nonmillennials' inability to process all the commercial information presented might lead to higher levels of perceived intrusiveness (Ha, 2017).

From a complementary approach, previous studies have shown that age may affect individuals' preferences as to how information is presented to be processed (Nguyen et al., 2017; Soroka et al., 2006). Consumers tend to value information related to product and services differently over the course of their lives. Younger people consider entertainment value the most important criterion, while older people choose media primarily based on information value (Fang et al., 2016; Phillips and Sternthal, 1977). Thus, millennials tend to look more frequently for entertainment content than non-millennials (Casaló et al., 2017b); thus, millennials may develop favorable predispositions to advertising messages presented in more dynamic and popular ways, such as those appearing in Instagram Stories (Hsieh et al., 2012).

Consequently, we propose:

H2. The effect of social media format on ad effectiveness is moderated by age, such that (a) ad attitude, (b) (reduced) ad intrusiveness and (c) loyalty will be enhanced in Instagram Stories for millennials, and in Facebook Wall for non-millennial users.

2.2.3 The moderating effect of gender. Many studies have examined the role of gender in consumers' orientation toward online commercial activities (Shi et al., 2016) and, more specifically, in social media use (Alalwan et al., 2017; Muscanell and Guadagno, 2012; Thelwall, 2008). Gender is considered a key segmentation variable in marketing and plays a key role in shaping consumers' evaluation of products and services (Holbrook, 1986). These gender differences have important effects on how advertising is processed (Goodrich, 2014), with clear implications for effectiveness (Rodgers and Thorson, 2017). Previous research confirms that gender clearly alters preferences toward social media, their use, and promotional activities on 
these platforms (Lebel and Danylchuk, 2012; Ragowsky and Awad, 2008). Therefore, understanding gender differences helps companies and advertisers develop more precise segmentation and marketing strategies according to value needs (Lee, 2011; Shi et al., 2016; Zhang et al., 2015).

Gender role expectation theory suggests that women tend to be more social than men, who are more focused on task-related events (Gefen and Straub, 1997; Zhou et al., 2014). In this regard, women, with their more social orientation (Sheldon and Bryant, 2016), spend more time sharing and collecting information in social media platforms than men (Acar, 2008; Sheldon, 2008). In as much as online platforms are valued for their social significance, women are more likely to be active users, commenting, following and interacting on socialfocused platforms than men (Sheldon and Bryant, 2016). Given the extensive possibility of Instagram Stories as a social medium due to its numerous social interaction features (e.g. moment sharing, closeness, immediacy, tags, etc.), we propose that ads in this medium might be more favorably received by women than men.

On the other hand, prior marketing research has also found information processing differences between the genders. According to priming theory, women are "comprehensive processors," who focus on integrating detailed information, whereas men are "selective processors," who rely on schemas and heuristics (Meyers-Levy and Maheswaran, 1991). When processing commercial information men follow simple rules and try to use as few resources as possible. In contrast, women spread their attention across a larger number of advertising stimuli (Goodrich, 2014). In a dynamic social media platform, such Instagram Stories, where users have a large quantity of information and interactive possibilities available during a short period, women may be able to focus more comprehensively on different types of information and process the advertising more effectively than men, who might more easily process stable information (i.e. Facebook Wall).

Accordingly, $H 3$ is proposed:

H3. The effect of social media format on ad effectiveness is moderated by gender, such that (a) ad attitude, (b) (reduced) ad intrusiveness and (c) loyalty will be enhanced in Instagram Stories for women and in Facebook Wall for men users.

\section{Method}

The research procedure consisted of an online survey in which each participant had to visit her/ his own social media site before answering the questionnaire. We recruited 308 individuals through direct links posted on the university website and shared among students, family, colleagues, and participants in a previous research project unrelated to the present study. The research was presented in Google Forms as an academic study on social media. After a short presentation, the participants were instructed to navigate through one of the three social networks for one minute. To ensure sufficient sample size in each group, the study website was arranged to assign participants randomly to one of the three conditions: Facebook Wall, Instagram Wall and Instagram Stories. Participants had to visit the assigned social medium using their own user account and to navigate through it as normal. Thereafter, they had to return to the study website to answer a questionnaire about their recent social media experience and some specific questions about the ad appeared during that time; participants were instructed to focus on the first ad if more than one ad appeared during their navigation. After removal of five respondents who did not complete the survey or watch any ads during their navigation, the final sample consisted of 303 valid responses (Facebook Wall, $N=103$; Instagram Wall, $N=100$; and Instagram Stories, $N=100$ ). The participants' ages ranged from 18 to 60, 33 years being the average; of the total, 56,77 per cent were millennials (aged below 31 years), and 63.03 per cent were women. Despite some bias toward women and younger users, 
the characteristics of the sample are similar to those of Spanish users of social media in terms of age and gender (IAB, 2018). A small pretest with 26 subjects, who did not thereafter participate in the main study, was performed to check the subjects' understanding of the initial instructions, the measurement instruments, and to assess the time required to complete the exercise.

\section{Instagram Stories versus Facebook Wall}

\subsection{Measurement}

Measurement scales for the questionnaire were obtained from different sources based on the theoretical content of each variable. Table I indicates the scale used to measure each construct and the source.

To test the validity of our scales (Table II), we also tested for construct reliability, and convergent and discriminant validity. Construct reliability was assessed by means of Cronbach's $\alpha$ and the composite reliability indicator, and we confirmed that the values for each scale were higher than the recommended 0.65 threshold (Steenkamp and Geyskens, 2006). To check convergent validity, we confirmed that the factor loadings of the confirmatory model were statistically significant (at 0.01) and higher than 0.5 (Steenkamp and Geyskens, 2006). The average variance extracted (AVE) values were also greater than 0.5 (Fornell and Larcker, 1981). The items of each scale correlated positively and converged on only one construct, such that the factorial analyses showed three factors with eigenvalues higher than 1, confirming the dimensionality of our research instrument. The proportion of variance explained was 42.85, 74.75 (accumulated) and 87.88 per cent (accumulated), respectively, the last being higher than the 0.60 threshold proposed by Hair et al. (1998). Discriminant validity was also confirmed by corroborating that the correlations

\begin{tabular}{|c|c|c|}
\hline Construct & Measurement & Adapted from \\
\hline Ad attitude ${ }^{a}$ & $\begin{array}{l}\text { The ad was unpleasant/pleasant } \\
\text { The ad was not at all likable/likable }\end{array}$ & Lau-Gesk and Meyers-Levy (2009) \\
\hline Intrusiveness $^{\mathrm{b}}$ & $\begin{array}{l}\text { The ad was intrusive } \\
\text { The ad was disturbing } \\
\text { The ad was distracting }\end{array}$ & Li et al. (2002) \\
\hline Loyalty $^{\mathrm{b}}$ & $\begin{array}{l}\text { I intend to get more information about the advertised } \\
\text { product/service } \\
\text { I intend to buy the advertised product/service } \\
\text { I would recommend the advertised product/service } \\
\text { I would disseminate information about the } \\
\text { advertised product/service in social media }\end{array}$ & Chi and Qu (2008) \\
\hline
\end{tabular}

Notes: ${ }^{a}$ Seven-point bipolar scale; ${ }^{b}$ seven-point Likert scale

Table I.

Constructs, scale items and source

\begin{tabular}{lcccccc}
\hline & Cronbach's alpha & CR & AVE & Ad attitude & $\begin{array}{c}\text { Perceived } \\
\text { intrusiveness }\end{array}$ & $\begin{array}{c}\text { Loyalty } \\
\text { intentions }\end{array}$ \\
\hline Ad attitude & $0.86 \mathrm{a}$ & 0.97 & 0.95 & 0.97 & & \\
Perceived intrusiveness & 0.94 & 0.96 & 0.90 & 0.18 & 0.95 & \\
Loyalty intentions & 0.87 & 0.95 & 0.83 & 0.36 & -0.19 & 0.91
\end{tabular}

Notes: Diagonal elements (bold figures) are the square root of the AVE (the variance shared between the constructs and their measures). Off-diagonal elements are the correlations among variables. CR: composite reliability. ${ }^{a}$ Cronbach's $\alpha$ has been replaced by the Spearman correlation for ad attitude two-item scale

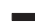


SJME

23,1

78

between constructs were lower than the square root of the AVE for each construct (Fornell and Larcker, 1981).

In addition, we tested for distribution normality and for the absence of multicollinearity problems, as depicted in Table III. The items in each variable present skewness and kurtosis values of \pm 2 , which are considered acceptable indicators of distribution normality (Garson, 2012). Only one item (LOY4) has a 2.88 kurtosis value which is also considered normal as it falls within the acceptable range of \pm 10 (Kline, 2011). A simple and obvious way to detect multicollinearity is to check the correlation matrix for the variables. The bi-variate correlations between the variables were between -0.23 and 0.36 , values which are lower than the correlations, above 0.70 or 0.90 , usually related to multicollinearity problems. In addition, the variance inflation factor for each item was below the established limit of 10 (Hair et al., 1998). Thus, there is no evidence of multicollinearity in the measurement instrument.

\section{Results}

First, to test the global effects of social media format, age and gender on the three dependent variables (i.e. ad attitude, intrusiveness and loyalty), we carried out a multivariate analysis of variance (MANOVA). The results of the MANOVA indicate that at least one of the dependent variables is significantly affected in isolation by social media format (Wilks's $\lambda=0.91, \mathrm{~F}(6,578)=4.89, p<0.01)$, and gender (Wilks's $\lambda=0.96, \mathrm{~F}(3,289)=3.76, p<0.05)$, but not by age (Wilks's $\lambda=0.98, \mathrm{~F}(3,289)=1.63, p>0.10)$. Interestingly, the interaction effect between social media format and age significantly affects one or more of the dependent variables (Wilks's $\lambda=0.93, \mathrm{~F}(6,578)=3.64, p<0.01$ ), but the interaction effect between social media and age is not significant (Wilks's $\lambda=0.97, \mathrm{~F}(6,578)=1.34, p>0.10$ ).

To examine more closely the effects on each dependent variable we carried out an analysis of variance (ANOVA) for each them, considering all the different conditions: Facebook Wall, Instagram Wall and Instagram Stories. The results reveal that the social media in which ads are presented influence attitude toward the ads $(\mathrm{F}(1,302)=6.07, p<$ $0.01)$ and intrusiveness $(\mathrm{F}(1,302)=14.53, p<0.01)$, but not loyalty $(\mathrm{F}(1,302)=0.12, p>$ 0.10). Table IV presents the descriptive statistics.

To test H1, which proposes that Instagram Stories has higher ad effectiveness than Facebook Wall, we carried out an Honestly Significant Difference test (HSD Tukey). In support of $H 1$ a, Instagram Stories' ads elicit a more favorable attitude than Facebook Wall $(p<0.01$, HSD Tukey test). Attitude toward the ad is also higher in Instagram Stories than in Instagram Wall ( $p<0.10$, HSD Tukey test), indicating that the influence is not due to the

Table III.

Normality and multicollinearity tests: skewness, kurtosis and VIF indicators

\begin{tabular}{lccr}
\hline Item & Skewness & Kurtosis & VIF \\
\hline ADATT1 & 1.15 & 1.14 & 5.00 \\
ADATT2 & 1.37 & 1.83 & 5.00 \\
INTRU1 & 0.71 & -0.48 & 4.41 \\
INTRU2 & 0.68 & -0.71 & 5.25 \\
INTRU3 & 0.82 & -0.38 & 4.20 \\
LOY1 & 1.06 & -0.08 & 3.94 \\
LOY2 & 1.40 & 0.95 & 4.46 \\
LOY3 & 1.23 & 0.40 & 2.67 \\
LOY4 & 1.93 & 2.88 & \\
Note: VIF = Variance inflation factor & &
\end{tabular}


social media but to the social media format. Contrary to our expectations, Instagram Stories ads do not reduce, but increase, levels of ad intrusiveness in comparison to Facebook Wall $(\phi<0.01)$. These results are contrary to $H 1 b$ and suggest the opposite effect: Instagram Stories ads are more intrusive than Facebook Wall and Instagram Wall ads $(\phi<0.01)$. Finally, we tested ad effectiveness in terms of loyalty, but the differences between Instagram Stories and the other two platforms are not significant ( $p>0.10$ HSD Tukey test). Thus, H1c is not supported. In addition, the differences between Facebook Wall and Instagram Wall were not significant for any of the three dependent variables ( $\phi>0.10$ HSD Tukey test), suggesting that advertising effectiveness is similar in both platforms when using wall formats.

Second, to test $H 2$, which proposes that the ad effectiveness of a social media format is moderated by age, we used analysis of variance (ANOVA). Table V presents the descriptive statistics of advertising effectiveness by social media format and age. The interaction effect between social media format and age is not significant in attitude toward the ad as the dependent variable $(\mathrm{F}<1)$. Thus, the moderation effect on attitude proposed in $H 2 a$ is rejected. In support of $H 2 b$, the interaction effect between age and social media format on intrusiveness is significant $(\mathrm{F}(1,302)=5.96, p<0.01)$. More specifically, the results show that Facebook Wall ads are more intrusive for millennial than for non-millennial users $(\mathrm{F}(1$, $102)=11.08, p<0.01$ ); in turn, Instagram Stories and Instagram Wall ads are less intrusive for millennial than for non-millennial users, although the differences are not significant (respectively $\mathrm{F}(1,99)=1.45, p>0.10$, and $\mathrm{F}(1,99)=1.74, p>0.10)$. Finally, our results support the interaction effect between age and social media advertising format on loyalty $(\mathrm{F}$ $(1,302)=3.34, p<0.05)$, in support of H2c. As presented in Table V, non-millennials tend to be more loyal to Facebook Wall ads, whereas millennials tend to be more loyal to Instagram Stories and Instagram Wall advertising (although the difference is only significant in the Instagram Wall condition, $\mathrm{F}(1,99)=14.14, p<0.01)$. Thus, the results reveal similar patterns of user responses in Instagram Wall and Instagram Stories in terms of attitude toward the ad, intrusiveness and loyalty. In this case, our findings suggest that the moderating effect of age on advertising effectiveness is more related to the social media (Instagram vs Facebook) than to format (Stories vs Wall).

A further ANOVA analysis was performed to test our $H 3$, as to whether gender moderates the influence of social media format on ad effectiveness. Table VI provides the descriptive statistics. The results indicate that the moderation effect on ad attitude proposed by $H 3 a$ is not supported. In terms of intrusiveness, we observe that it is influenced directly by gender $(\mathrm{F}(1,302)=6.15, p<0.05)$. More specifically, men perceive ads on all platforms as more intrusive than women. Nevertheless, the interaction effect between social media format and gender on ad intrusiveness is not significant, which indicates that $H 3 b$ is not supported. In turn, the interaction effect between social media format and gender on loyalty is significant $(F(1,302)$ $=3.12, p<0.05$ ), in support of $H 3 c$. In this sense, Facebook Wall significantly increases loyalty among men compared to women $(\mathrm{F}(1,102)=4.01, p<0.05)$. Loyalty in Instagram Wall also tends to be higher for men than for women, although the difference is not significant

\begin{tabular}{|c|c|c|c|c|c|c|c|c|c|}
\hline \multirow[b]{2}{*}{ Dependent variable } & \multicolumn{2}{|c|}{ Facebook Wall } & \multicolumn{2}{|c|}{ Instagram Wall } & \multicolumn{2}{|c|}{ Instagram Stories } & \multicolumn{2}{|c|}{ ANOVA } & \multirow{5}{*}{$\begin{array}{r}\text { Table IV. } \\
\text { Descriptive statistics } \\
\text { by social media } \\
\text { format }\end{array}$} \\
\hline & Mean & (SD) & Mean & (SD) & Mean & $(S D)$ & $F(2,300)$ & $p$ & \\
\hline Ad attitude & 2.00 & (1.49) & 2.22 & $(1.67)$ & 2.63 & (1.13) & 6.07 & 0.00 & \\
\hline Ad intrusiveness & 2.56 & (1.43) & 2.82 & (1.49) & 3.76 & (1.30) & 14.53 & 0.00 & \\
\hline Loyalty intentions & 2.06 & (1.46) & 2.09 & (1.79) & 2.16 & (1.46) & 0.12 & 0.88 & \\
\hline
\end{tabular}


SJME

23,1

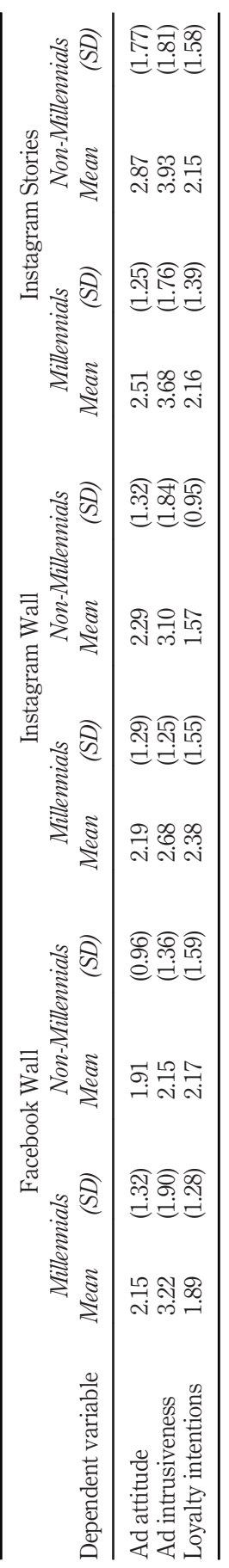

Table V.

Descriptive statistics by social media format and age 
$(\mathrm{F}(1,99)=0.18, p>0.10)$. In turn, loyalty in Instagram Stories tends to be higher among women than men, but this difference is not significant $(\mathrm{F}(1,99)=2.36, p>0.10)$. Thus, in the case of the results of gender influence on loyalty, Instagram Wall has a similar pattern to Facebook Wall, suggesting that gender differences in advertising effectiveness are due to the format (Stories vs Wall) rather than the social media (Instagram vs Facebook).

\subsection{Post hoc analysis: triple interaction effect and users' profiles}

After observing the moderation effects of age and gender in isolation, a post hoc analysis was carried out to test a possible triple interaction effect between social media format, age, and gender on ad effectiveness. In other words, the moderating effect of age may be simultaneously moderated by gender, such that the impact of each of the variables may depend on the other. To test this proposition, we conducted an ANOVA analysis of the direct effect of each dependent variable and the interaction effect of the combinations between them, including the triple interaction effect.

The analyses of attitude toward the ad and ad intrusiveness as the dependent variables show significance for the direct or interaction effects mentioned in the previous sections, but no triple interaction effects were found. The most interesting results are found with loyalty as the dependent variable. Specifically, the results confirm a significant triple interaction effect of social media format, age, and gender $(\mathrm{F}(1,302)=3.62, p<0.05)$.

Figures 1-3 help to disentangle this unexpected interaction effect. In concrete terms, the results indicate that millennials of both genders have similar loyalty intentions in each of the social platforms. In the case of Instagram Wall, millennial users are significantly more loyal to advertising on that social media format than non-millennial users $(\mathrm{F}(1,99)=7.30, p<$ 0.01). In Instagram Stories and Facebook Wall, non-millennial users differ in their loyalty intentions depending on gender and social media platform. Non-millennial men present significantly higher levels of loyalty than non-millennial women when shown ads in Facebook Wall $(\mathrm{F}(1,62)=5.90, p<0.05)$. In turn, non-millennial men present significantly lower levels of loyalty than non-millennial women when shown ads in Instagram Stories $(\mathrm{F}(1,33)=6.24, p<0.05)$.

In sum, the results of the post hoc analyses reveal that Instagram Wall increases loyalty among both millennial men and millennial women (but not among non-millennials); Instagram Stories might increase loyalty among millennial users of both sexes and nonmillennial women, whereas Facebook Wall might be particularly effective to increase loyalty intentions among non-millennial men.

To drill down into these findings, we examined non-millennial differential profiles in social media platforms, depending on gender. To do so, we analyzed two items included at the end of the questionnaire regarding intensity of social media use and the following of influencers' profiles. Specifically, we presented an eight-point scale of frequency of use (number of times that the individual uses the social media platform, from $1=$ Less than once

\begin{tabular}{|c|c|c|c|c|c|c|c|c|c|c|c|c|c|}
\hline \multirow[b]{3}{*}{ Dependent variable } & \multicolumn{4}{|c|}{ Facebook Wall } & \multicolumn{4}{|c|}{ Instagram Wall } & \multicolumn{4}{|c|}{ Instagram Stories } & \multirow{6}{*}{$\begin{array}{r}\text { Table VI. } \\
\text { Descriptive statistics } \\
\text { by social media } \\
\text { format and gender }\end{array}$} \\
\hline & Won & men & $M$ & & Won & nen & $M e$ & & Won & nen & $M e$ & $e n$ & \\
\hline & Mean & $(S D)$ & Mean & $(S D)$ & Mean & (SD) & Mean & $(S D)$ & Mean & $(S D)$ & Mean & $(S D)$ & \\
\hline Ad attitude & 2.05 & (1.18) & 1.94 & $(1.03)$ & 2.25 & (1.23) & 2.20 & (1.40) & 2.73 & (1.41) & 2.40 & (1.53) & \\
\hline Ad intrusiveness & 2.47 & $(1.48)$ & 2.71 & $(1.90)$ & 2.54 & (1.40) & 3.24 & (1.52) & 3.61 & $(1.70)$ & 4.13 & (1.92) & \\
\hline Loyalty intentions & 1.82 & $(1.24)$ & 2.41 & $(1.72)$ & 2.05 & (1.37) & 2.17 & $(1.50)$ & 2.30 & (1.59) & 1.81 & $(0.96)$ & \\
\hline
\end{tabular}


SJME

23,1

\section{2}

\section{Figure 1.}

Triple moderation effect of age and gender on loyalty in Facebook Wall

\section{Figure 2.}

Triple moderation effect of age and gender on loyalty in Instagram Wall
Figure 3.

Triple moderation effect of age and gender on loyalty in Instagram Stories
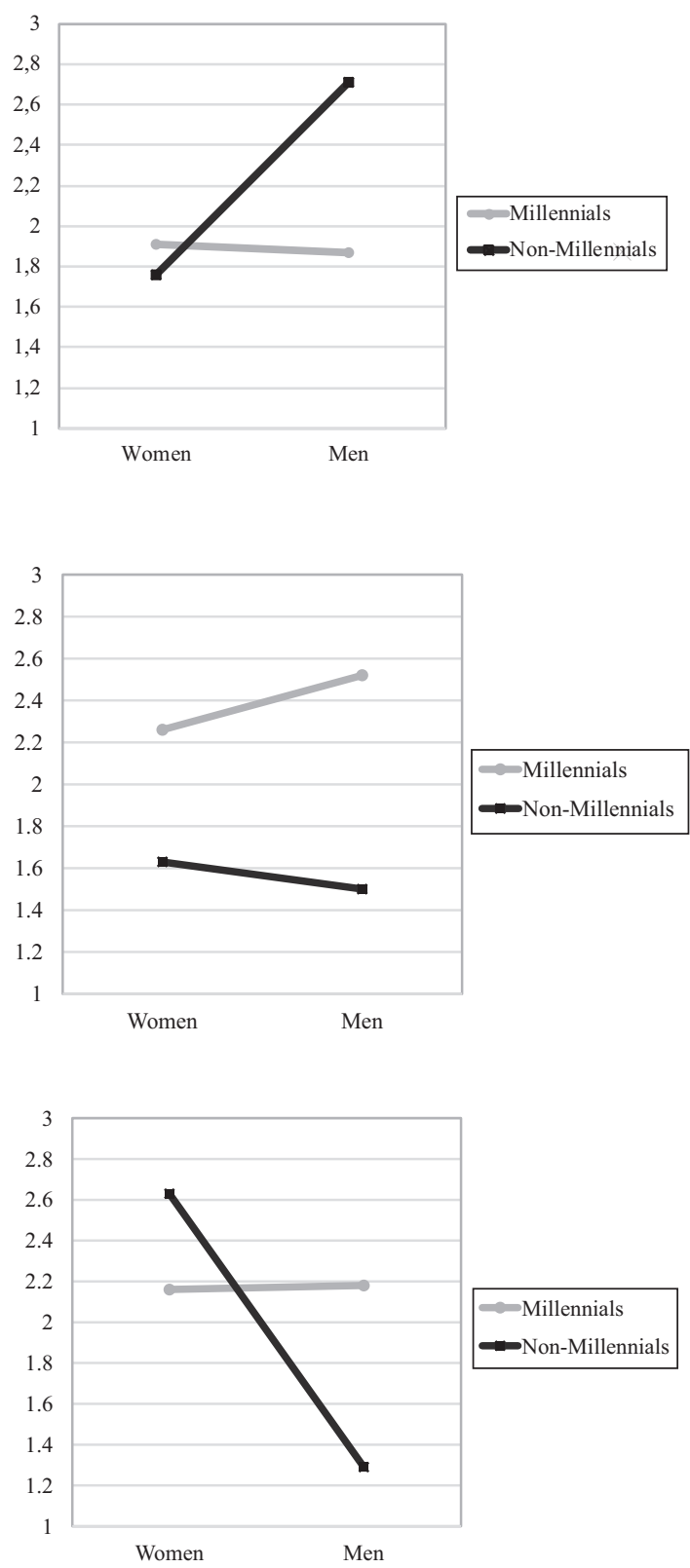

per month, to 8 = More than 20 times per day), adapted from Belanche et al. (2017b), and a question as to whether the respondent was following an influencer and who that was.

When comparing non-millennial women (women over 30 years old) to the rest of the sample, the results indicate that they do not differ in their frequency of use and influencer-following 
behavior. However, the results do indicate that social media use by non-millennial men (men over 30) differs from the rest of the sample. Specifically, non-millennial men tend to use social media less frequently than the other groups of users $\left(\mathrm{M}_{\text {Non-MillennialsMen }}=4.94, \mathrm{M}_{\mathrm{Others}}=6.12\right.$; $t(301)=4.31, p<0.01)$. In addition, the percentage of non-millennial men following at least one influencer is significantly lower (21.7 per cent) than the percentage of users in the other groups who follow one or more influencers (42.1 per cent) $\left(X^{2}=6.76, p<0.01\right)$.

Table VII summarizes the results of the hypotheses testing and the main research findings for practical purposes.

\section{Discussion}

Online advertising is today the most important advertising channel and it is expected to continue growing and evolving during the next years. Of the new online advertising possibilities, the advertising industry is paying special attention to social media platforms

\begin{tabular}{|c|c|c|c|c|}
\hline Hypothesis & Formulation & Result & Practical findings & \\
\hline$H 1 a$ & $\begin{array}{l}\text { Ad attitude } \\
\text { Instagram Stories }>\text { Facebook } \\
\text { Wall }\end{array}$ & Supported & $\begin{array}{l}\text { Attitude toward ads is higher in Instagram } \\
\text { Stories than in Facebook Wall and } \\
\text { Instagram Wall }\end{array}$ & \\
\hline$H 1 b$ & $\begin{array}{l}\text { Ad intrusiveness } \\
\text { Facebook Wall }>\text { Instagram } \\
\text { Stories }\end{array}$ & $\begin{array}{l}\text { Not supported } \\
\text { (opposite effect) }\end{array}$ & $\begin{array}{l}\text { Intrusiveness perception toward ads is } \\
\text { higher in Instagram Stories than in } \\
\text { Facebook Wall and Instagram Wall }\end{array}$ & \\
\hline$H 1 c$ & $\begin{array}{l}\text { Ad loyalty intentions } \\
\text { Instagram Stories }>\text { Facebook } \\
\text { Wall }\end{array}$ & Not supported & Please see $H 2 c, H 3 c$ and post hoc c & \\
\hline$H 2 a$ & $\begin{array}{l}H 1 a \text { is higher for millennials } \\
\text { than for non-millennials }\end{array}$ & Not supported & Please see $H 1 a$ & \\
\hline$H 2 b$ & $\begin{array}{l}H 1 b \text { is higher for millennials } \\
\text { than for non-millennials }\end{array}$ & Supported & $\begin{array}{l}\text { Ad intrusiveness in different social media } \\
\text { depends on age. In particular, millennials } \\
\text { perceive ads on Facebook Wall as more } \\
\text { intrusive }\end{array}$ & \\
\hline$H 2 c$ & $\begin{array}{l}H 1 c \text { is higher for millennials } \\
\text { than for non-millennials }\end{array}$ & Supported & $\begin{array}{l}\text { Loyalty toward ads in different social media } \\
\text { depends on age. In particular, millennials } \\
\text { are more loyal to ads in Instagram Wall }\end{array}$ & \\
\hline H3a & $\begin{array}{l}H 1 a \text { is higher for women than } \\
\text { for men }\end{array}$ & Not supported & Please see $H 1 a$ & \\
\hline$H 3 b$ & $\begin{array}{l}H 1 b \text { is higher for women than } \\
\text { for men }\end{array}$ & Not supported & Please see $H 1 b$ and $H 2 b$ & \\
\hline$H 3 c$ & $\begin{array}{l}H 1 c \text { is higher for women than } \\
\text { for men }\end{array}$ & Supported & $\begin{array}{l}\text { Loyalty toward the ad in different social } \\
\text { media depends on gender. In particular, } \\
\text { men are more loyal to ads in Facebook Wall }\end{array}$ & \\
\hline Post hoc a & $\begin{array}{l}H 1 a \text { is simultaneously } \\
\text { affected by age and gender }\end{array}$ & Not supported & Please see $H 1 a$ & \\
\hline Post hoc b & $\begin{array}{l}H 1 b \text { is simultaneously affected } \\
\text { by age and gender }\end{array}$ & Not supported & Please see $H 1 b$ and $H 2 b$ & \\
\hline Post hoc c & $\begin{array}{l}H 1 c \text { is simultaneously affected } \\
\text { by age and gender }\end{array}$ & Supported & $\begin{array}{l}\text { Loyalty toward ads is influenced by the } \\
\text { interaction between social media format, } \\
\text { age, and gender. Facebook Wall increases } \\
\text { loyalty among non-millennial men. } \\
\text { Instagram Wall increases loyalty among } \\
\text { millennials of both genders. Instagram } \\
\text { Stories increases loyalty among millennials } \\
\text { of both genders and non-millennial women }\end{array}$ & $\begin{array}{r}\text { Table VII. } \\
\text { Summary of results, } \\
\text { hypotheses testing } \\
\text { and findings }\end{array}$ \\
\hline
\end{tabular}


SJME

23,1

because of their growth and impact on users' lives. Social media platforms, which have different features, offer various opportunities to advertisers to attract the consumer's attention and to persuade them as part of the competitive process. As a consequence, advertisers and researchers need to learn more about the potential of each social media platform. In this context, our study contributes to the understanding of how the specific characteristics of social media affect advertising effectiveness in terms of attitude toward an ad, intrusiveness and loyalty.

To help advertisers choose among these media, this research focuses on the two leading social media platforms - Facebook and Instagram. Facebook, considered an informationoriented medium (Sheldon and Bryant, 2016), has the largest number of users. In the consolidated format of Facebook Wall, advertisers present their ads usually in a static and structured form. In contrast, Instagram, which has the highest growth rate of all social media platforms, is more self-promotion oriented (Sheldon and Bryant, 2016), and its particularly dynamic and popular Instagram Stories feature is increasing its value for personal and commercial brands. Instagram Stories offers to advertisers a new way to communicate with users through a full screen, ephemeral, dynamic and interactive display with high entertainment value, which will probably soon be extended to most other social media platforms (Taylor, 2018).

This research concludes that advertising effectiveness varies depending on the social media format, and that the differences between the platforms are better understood through analysis of the differential perceptions and reactions toward the ads based on these features. Specifically, our results confirm that the more dynamic social-media formats (i.e. Instagram Stories) enhance users' attitudes toward an ad more than the more static formats (i.e. Facebook Wall and Instagram Wall). This result is consistent with previous studies which associate creative strategies with customer engagement, specifically dynamic visual messaging (Ashley and Tuten, 2015). In addition, this outcome is in line with our assumption about the self-promotional nature of Instagram Stories, which encourages users to be favorably predisposed to receive promotional content, whether from a person or a brand. Furthermore, this research considers that the social and interactive entertainment characteristics of Instagram Stories, such as augmented reality stickers, might lead users to have more favorable attitudes toward its ads than to those appearing in Facebook. In this line, the Stories format represents an advance on already innovative interactive advertising formats, such as skippable video ads (e.g. pre-roll in-stream YouTube ads). The way of viewing Stories may be similar to YouTube, where the video ads appear within the navigation experience as additional dynamic content, having the same format as the rest of the content, but can be skipped by the user after (s)he has spent some initial time processing the information (Belanche et al., 2017b). Indeed, skippable video ads have been proved to be more effective because of their interactive and user-centered features, than non-skippable video ads (Belanche et al., 2017a; Pashkevich et al., 2012). These features might be more easily linked to stories ads than to wall ads.

However, and contrary to our initial expectations, ads presented on the more dynamic Instagram Stories are perceived as more intrusive than those more static ads presented in Facebook Wall. Our results accord with Pikas and Sorrentino (2014), which affirm that the majority of respondents are annoyed by advertising on their favorite social media. This interesting result is not totally surprising, as some aspects of Instagram Stories may generate a negative advertising experience. On the one hand, the whole system of Instagram Stories ads is based on the frequent and fast display of ephemeral contents that users tend to check at any time and which could increase stress among users navigating through the platform. Furthermore, Instagram Stories does not pre-announce that commercial content 
will be broadcast during the ordered series of stories; ads suddenly appear to interrupt the navigation experience. In addition, Stories tends to incorporate flashing or animated tags and calls to action embedded in the full screen. Thus, this format includes aspects, such as ad size, traditionally associated with feelings of intrusiveness (Li, et al., 2002). In contrast, Facebook Wall ads are shown only in a part of the screen, which allows users to continue to watch other content, which could decrease intrusiveness perceptions. In any case, although intrusiveness is related to negative advertising experience, previous literature on advertising admits that a certain level of intrusiveness (e.g. a big size ad) might be commercially beneficial, because this often leads to increased attention, information processing and memorization (Chatterjee, 2008).

Our research found that type of social media platform does not have a direct impact on loyalty. However, the interaction between social media platform and key personal variables (i.e. age and gender) makes a difference to the level of loyalty felt toward the advertised items. Thus, we conclude that basic characteristics of the user play a moderating role in determining social media effectiveness in terms of loyalty intentions toward advertised products and services.

With regard to the moderating effect of age, an interaction effect between age and social media platform was detected for both intrusiveness and loyalty. More precisely, our results confirm that Facebook Wall ads are less intrusive for non-millennial than for millennial users. Following Lang's (2000) limited capacity model, millennials may have acquired the ability to handle the most innovative aspects of social media platforms, such as the interactive, vivid, and short pieces of information on Instagram Stories (Teo, 2016). As to loyalty, our results support that millennials are more loyal to Instagram Stories ads than non-millennials, who tend to be more loyal to Facebook Wall ads. The narcissistic and entertainment focused preferences of millennials when using social media platforms (Sheldon and Bryant, 2016; Taylor, 2018) accustoms millennial consumers to interact and to process commercial inputs naturally, resulting in more positive purchase intentions. Thus, due to the dynamic and the self-promotional character of Instagram Stories, millennials might perceive Instagram Stories ads as less intrusive and, consequently, they will develop greater loyalty intentions toward them than to ads presented in Facebook Wall.

Our research also helps understand the role of gender in advertising effectiveness in social media. The results show that, in general, men perceive ads as more intrusive than women. Following the priming theory, this effect could be explained by women's ability to integrate detailed information and spread their attention across a larger number of advertising stimuli than men (Goodrich, 2014). In other words, because men are more task oriented (Meyers-Levy and Maheswaran, 1991), it seems that any interruption, such as those in Instagram Stories, leads them to perceive higher levels of intrusiveness. In contrast, the comprehensive capacity of women (Meyers-Levy and Maheswaran, 1991) allows them to process information without losing sight of the ultimate goal, which makes the ads seem less intrusive.

On the other hand, women generate higher loyally to advertised items presented on Instagram Stories than to those advertised on Facebook Wall. These findings are in line with gender role expectation theory which argues that women are more social than men (Gefen and Straub, 1997; Sheldon and Bryant, 2016; Zhou et al., 2014). While men tend to be more task oriented, women spend more time sharing and collecting information in social media platforms (Acar, 2008; Sheldon, 2008); consequently, the results support that commercial information presented in a highly interactive social medium, such as Instagram, is more positively perceived by women. Similarly, the social and information processing character of women's navigation might make them generate greater loyal intentions (i.e. 
purchase, recommendations) than men to the advertised items in Instagram Stories; men are more loyal to items advertised in more static platforms, such as Facebook Wall.

In addition, our post hoc analyses found that non-millennial men are more loyal toward Facebook Wall ads than non-millennial women and millennials of both genders. In contrast, Instagram Stories has reduced loyalty intentions for non-millennial men. Millennials grew up during the "boom" of the globalized firms and are more impressed by creative interactive ads which have high levels of visual impact (Taylor, 2018). Moreover, our results reveal that, contrary to the stereotyped idea about the low brand loyalty of millennials, they like brands they view as part of their own identity (Taylor, 2018). In the case of women, loyalty intention in Instagram Stories is even higher for non-millennial women than for millennials. The more social character of women (Sheldon and Bryant, 2016), together with the importance that non-millennial women might give to informational social value (Fang et al., 2016), may lead them to perceive Instagram Stories as a useful informational tool that might keep them abreast of the latest trends and help them communicate with peers (Acar, 2008; Sheldon, 2008). Our results also show that non-millennial men have less intense use of social media and follow less influencers than the other groups. In this sense, the results suggest than nonmillennial men tend to be less social in the digital context than women or millennials of both sexes. These findings suggest that a generational change effect seems to be at play; in relation to social media use, newer generations seem to be more socially oriented, with more general female behaviors (Sheldon and Bryant, 2016).

The inclusion of the Instagram Wall control group helps to identify whether advertising effectiveness differences between Instagram Stories and Facebook Wall are due to the kind of social media or to the kind of format (Stories vs Wall). In most cases, Instagram Wall provides similar values to Facebook Wall, suggesting that format is more important than social media. However, in terms of age, it seems that millennial users tend to be more loyal to Instagram than to Facebook, independent of the kind of Instagram ad format. In any case, the results suggest that Instagram Wall falls between the other two, but that it should not simply be assimilated into either of the other two social media or formats (e.g. post hoc results).

Looking at the advertising field in general, the findings of this research are particularly relevant because all advertising formats are evolving into shorter and more interactive supports (Belanche et al., 2017a). Users demand to be able to evaluate the information provided and judge whether they want to continue watching the ad. Moreover, the appearance of brand profiles contributes to obscure the differences between profile promotion and advertising. Users, and specifically millennials, interact with brands similarly to how they interact with other persons, via "like" or "share" buttons and comments, which loses the idea of receiving a commercial message (Taken Smith, 2012). Therefore, understanding how different groups of consumers face these innovations is crucial for improving advertising effectiveness and users' overall experience in social media.

\subsection{Managerial implications}

Since the first online ad appeared, until today, online advertising has moved forward to new and more interactive formats which take individuals' preferences into consideration. A wide number of advertising options other than social media platforms exist, and advertising professionals face the challenge of appropriately investing their limited budgets to reach the highest levels of marketing efficiency (Hofacker and Belanche, 2016). In this context, this research can help advertisers, firms and community managers achieve business success in the two most important social media platforms, Instagram and Facebook. 
First, our results show that Instagram Stories builds better attitudes toward ads than Facebook Wall. Professionals should note that users exposed to ads on Instagram Stories tend to generate a positive predisposition toward the ads and, consequently, to the products and services offered. The ephemeral, dynamic and interactive Instagram Stories could be very effective in flash sales and for other short-term objectives. This finding is in line with previous research on social media influence on impulse buying, which confirms that Instagram leads to higher consumer impulsive behaviors than Facebook, Pinterest and Twitter (Aragoncillo and Orús, 2018). Nevertheless, Instagram Stories ads are perceived as more intrusive than Wall formats. This negative experience may damage the strategic objectives of a campaign; this finding suggests that using Wall formats might be a better option to build long-term goals, such as brand equity (Dehghani and Tumer, 2015). Therefore, professionals should choose between social media platforms based on the principal goals of the advertising campaign. In addition, the selection of the social media platform should be based on the target audience, as we explain next.

Our research concludes that age is an important demographic factor for determining the perceived intrusiveness of advertising in both social media platforms. The results reveal that millennials perceive lower intrusiveness in an ad embedded in Instagram Stories than in Facebook Wall, whereas non-millennials perceive the opposite. In addition, millennials are more loyal to products and services advertised on Instagram Stories than on Facebook Wall. Thus, advertising professionals should focus on Instagram Stories when targeting millennial users, whereas they should focus on Facebook Wall when targeting nonmillennial users (especially men). As previously noted, a correct matching of campaign objectives, targets, and social media platform is crucial for advertising success (Bleier and Eisenbeiss, 2015). Administering exposure to the ads will not be complex, as both social media are owned by Facebook, and thus advertisers can use the same Facebook-developed bidding system to manage both their Instagram and Facebook campaigns. Like other bidding systems, such as Google AdWords, Facebook Ads is a visual tool which allows advertisers to segment the target, program the budgets allocated to each campaign, and schedule the advertising broadcasting. Advertisers should be trained on the use of this system as part of their professional skills; hitherto, they have usually focused on Google AdWords.

Our research also highlights that gender is a key factor in determining advertising effectiveness in social media platforms. Overall, women perceive advertising as less intrusive than men and are also more loyal to products or services advertised in Instagram Stories. Thus, Instagram Stories seems to be an excellent choice when targeting women. In any case, professionals should closely examine these gender differences to better focus the advertising stimuli to the correct target market. Women attach importance to information provided by peers, which is crucial to spread the commercial message virally. Advertisers should exploit all the new opportunities offered by social media platforms to segment their advertising targets with detail and precision.

Finally, this research focuses on advertising effectiveness, but to improve advertisers' efficiency, an economic perspective in terms of the cost of advertising in each media should be included. Efficiency relates not only to output (e.g. attitude, loyalty) but also to the input (i.e. usually the costs) invested to achieve that output; in other words, to reach the highest levels of effectiveness while incurring the lowest costs to achieve that goal. A common economic indicator in social media is CPM (cost per thousand impressions), the lower the better. Recent studies show that the cost of advertising is much higher in Facebook than in Instagram; more precisely, CPM can be double for Facebook than for Instagram (Smith, 2018). Thus, given that Instagram Stories ads are cheaper than Facebook ads, advertisers 
should use Instagram Stories in those cases where campaigns on that medium are already more effective. In turn, in the cases where Facebook ads are more effective, advertisers should calculate whether the increase of effectiveness is worth paying the increased price of Facebook advertising. Furthermore, these analyses should be frequently updated, as the bidding system can be affected by special sales occasions, such as Christmas, "Black Friday", etc. Our research suggests that using Instagram Stories as an advertising platform seems to be an opportune effective strategy (especially when focusing on women and millennial men). Building an Instagram company profile might be an effective way to spread commercial messages without incurring additional advertising costs.

\section{Limitations and further research}

Despite the novel contribution of this study, it has several limitations that open new avenues for future research. First, our research design does not control for the specific ads broadcast in each social media platform. Although testing effectiveness during real users' navigation in their social media profiles increases the external validity of the research, the results could be affected by additional factors, such as the product; further research should replicate the study in lab settings (Belanche et al., 2017a) and with a probabilistic sample design. Second, we study Facebook and Instagram, currently the two leading social media platforms. The inclusion of other social media could help corroborate our hypotheses in different contexts. Indeed, further measures should be incorporated to better assess the persuasiveness of the advertising messages in each platform. Third, more detailed research into users' profile characteristics might help professionals to examine not only the demographic factors presented in this study but also other personal or situational factors, such as lifestyles. Fourth, it would be also interesting to compare the effectiveness of "Paid ads" versus "Non-paid ads" (e.g. stories presented to followers of the brand's profile) in Instagram Stories. Finally, a longitudinal study examining the evolution of advertising effectiveness in both social media platforms, Instagram and Facebook, might help academics and researchers better understand how changes in social media influence advertising over time.

\section{Note}

1. Facebook Stories was not included as a control group because when this study was carried out (May 2018), it had only been recently launched and did not include advertising.

\section{References}

Acar, A. (2008), "Antecedents and consequences of online social networking behavior: the case of facebook", Journal of Website Promotion, Vol. 3 Nos 1/2, pp. 62-83.

Alalwan, A.A., Rana, N.P., Dwivedi, Y.K. and Algharabat, R. (2017), "Social media in marketing: a review and analysis of the existing literature", Telematics and Informatics, Vol. 24 No. 7 , pp. $1177-1190$.

Allcott, H. and Gentzkow, M. (2017), "Social media and fake news in the 2016 election", Journal of Economic Perspectives, Vol. 31 No. 2, pp. 211-236.

Alter, J. (2018), "Instagram engagement rate data: average seconds on site", available at: www.yotpo. com/blog/instagram-engagement-rate/ (accessed 21 November 2018).

Aragoncillo, L. and Orus, C. (2018), "Impulse buying behaviour: an online-offline comparative and the impact of social media”, Spanish Journal of Marketing-ESIC, Vol. 22 No. 1, pp. 42-62. 
Ashley, C. and Tuten, T. (2015), "Creative strategies in social media marketing: an exploratory study of branded social content and consumer engagement", Psychology and Marketing, Vol. 32 No. 1, pp. 15-27.

Auschaitrakul, S. and Mukherjee, A. (2017), "Online display advertising: the influence of web site type on advertising effectiveness", Psychology and Marketing, Vol. 34 No. 4, pp. 463-480.

Aydin, S. and Özer, G. (2005), "The analysis of antecedents of customer loyalty in the Turkish mobile telecommunication market”, European Journal of Marketing, Vol. 39 Nos 7/8, pp. 910-925.

Barry, A.E., Bates, A.M., Olusanya, O., Vinal, C.E., Martin, E., Peoples, J.E., Jackson, Z.A., Billinger, S.A., Yusuf, A., Cauley, D.A. and Montano, J.R. (2016), "Alcohol marketing on twitter and instagram: evidence of directly advertising to youth/adolescents", Alcohol and Alcoholism, Vol. 51 No. 4, pp. 487-492.

Belanche, D., Flavián, C. and Pérez-Rueda, A. (2017a), "Understanding interactive online advertising: congruence and product involvement in highly and lowly arousing, skippable video ads", Journal of Interactive Marketing, Vol. 37, pp. 75-88.

Belanche, D., Flavián, C. and Pérez-Rueda, A. (2017b), "User adaptation to interactive advertising formats: the effect of previous exposure, habit and time urgency on ad skipping behaviors", Telematics and Informatics, Vol. 34 No. 7, pp. 961-972.

Bleier, A. and Eisenbeiss, M. (2015), "Personalized online advertising effectiveness: the interplay of what, when, and where", Marketing Science, Vol. 34 No. 5, pp. 669-688.

Brehm, J.W. (1966), A Theory of Psychological Reactance, Academic Press, New York, NY.

Bright, L.F. and Daugherty, T. (2012), "Does customization impact advertising effectiveness? An exploratory study of consumer perceptions of advertising in customized online environments", Journal of Marketing Communications, Vol. 18 No. 1, pp. 19-37.

Buffardi, L.E. and Campbell, W.K. (2008), "Narcissism and social networking web sites", Personality and Social Psychology Bulletin, Vol. 34 No. 10, pp. 1303-1314.

Casaló, L.V., Flavián, C. and Ibáñez-Sánchez, S. (2017a), "Antecedents of consumer intention to follow and recommend an instagram account”, Online Information Review, Vol. 41 No. 7, pp. 1046-1063.

Casaló, L.V., Flavián, C. and Ibáñez-Sánchez, S. (2017b), "Understanding consumer interaction on instagram: the role of satisfaction, hedonism, and content characteristics", Cyberpsychology, Behavior, and Social Networking, Vol. 20 No. 6, pp. 369-375.

Casaló, L.V., Flavián, C. and Ibáñez-Sánchez, S. (2018), "Influencers on instagram: antecedents and consequences of opinion leadership", Journal of Business Research, In Press.

Chatterjee, P. (2008), "Are unclicked ads wasted: enduring effects of banner and pop-up ad exposures on brand memory and attitudes", Journal of Electronic Commerce Research, Vol. 9, pp. 51-61.

Chen, Y.L., Tang, K., Wu, C.C. and Jheng, R.Y. (2014), "Predicting the influence of users' posted information for eWOM advertising in social networks", Electronic Commerce Research and Applications, Vol. 13 No. 6, pp. 431-439.

Chi, C.G.Q. and Qu, H. (2008), "Examining the structural relationships of destination image, tourist satisfaction and destination loyalty: an integrated approach", Tourism Management, Vol. 29 No. 4, pp. 624-636.

Cho, C.H. and Cheon, H.J. (2004), "Why do people avoid advertising on the internet?", Journal of Advertising, Vol. 33 No. 4, pp. 89-97.

Chu, S.C. and Kim, J. (2018), “The current state of knowledge on electronic word-of-mouth in advertising research", International Journal of Advertising, Vol. 37 No. 1, pp. 1-13.

Constine, J. (2018), "Instagram hits 1 billion monthly users, up from 800M in September", available at: https:// techcrunch.com/2018/06/20/instagram-1-billion-users/?guccounter=1 (accessed 28 November 2018).

Cooper, P. (2018), "Social media advertising stats that matter to marketers in 2018", available at: https:// blog.hootsuite.com/social-media-advertising-stats/ (accessed 26 November 2018). 
Cornelis, E. and Peter, P.C. (2017), "The real campaign: the role of authenticity in the effectiveness of advertising disclaimers in digitally enhanced images", Journal of Business Research, Vol. 77, pp. 102-112.

Cronin, J.J., Jr, Brady, M.K. and Hult, G.T.M. (2000), “Assessing the effects of quality, value and customer satisfaction on consumer behavioral intentions in service environments", Journal of Retailing, Vol. 76 No. 2, pp. 193-218.

Danaher, P.J. (2017), “Advertising effectiveness and media exposure”, In Handbook of Marketing Decision Models, Springer, Cham, pp. 463-481.

De Bruyn, A. and Lilien, G.L. (2008), "A multi-stage model of word-of-mouth influence through viral marketing”, International Journal of Research in Marketing, Vol. 25 No. 3, pp. 151-163.

Deal, J.J., Altman, D.G. and Rogelberg, S.G. (2010), "Millennials at work: what we know and what we need to do (if anything)", Journal of Business and Psychology, Vol. 25 No. 2, pp. 191-199.

Dehghani, M. and Tumer, M. (2015), "A research on effectiveness of facebook advertising on enhancing purchase intention of consumers", Computers in Human Behavior, Vol. 49, pp. 597-600.

Eagly, A.H. and Chaiken, S. (1993), The Psychology of Attitudes, Harcourt Brace Jovanovich College Publishers.

Erkan, I. and Evans, C. (2016), "The influence of eWOM in social media on consumers' purchase intentions: an extended approach to information adoption", Computer Human Behaviour, Vol. 61, pp. 47-55.

Fang, J., Wen, C., George, B. and Prybutok, V.R. (2016), "Consumer heterogeneity, perceived value, and repurchase decision-making in online shopping: the role of gender, age, and shopping motives", Journal of Electronic Commerce Research, Vol. 17 No. 2, pp. 116-131.

Flavián, C., Gurrea, R. and Orús, C. (2009), "The effect of product presentation mode on the perceived content and continent quality of web sites", Online Information Review, Vol. 33 No. 6, pp. 1103-1128.

Flavián, C., Gurrea, R. and Orús, C. (2012), “An integrative perspective of online foraging behavior with search engines”, Psychology and Marketing, Vol. 29 No. 11, pp. 836-849.

Fornell, C. and Larcker, D.F. (1981), "Evaluating structural equation models with unobservable variables and measurement error", Journal of Marketing Research, Vol. 18 No. 1, pp. 39-50.

Garson, G.D. (2012), Testing Statistical Assumptions, Statistical Associates Publishing, Asheboro, NC.

Gefen, D. and Straub, D.W. (1997), "Gender differences in the perception and use of e-mail: an extension to the technology acceptance model”, MIS Quarterly, Vol. 21 No. 4, pp. 389-400.

GlobalIndex (2018), "The latest social media trends to know in 2018", available at: www. globalwebindex.com/reports/social (accessed 27 November 2018).

Goldsmith, R.E., Lafferty, B.A. and Newell, S.J. (2000), "The impact of corporate credibility and celebrity credibility on consumer reaction to advertisements and brands", Journal of Advertising, Vol. 29 No. 3, pp. $43-54$.

Goodrich, K. (2014), "The gender gap: brain-processing differences between the sexes shape attitudes about online", Journal of Advertising Research, Vol. 54 No. 1, pp. 32-43.

Goodrich, K., Schiller, S.Z. and Galletta, D. (2015), "Consumer reactions to intrusiveness of online-video advertisements: do length, informativeness, and humor help (or hinder) marketing outcomes?", Journal of Advertising Research, Vol. 55 No. 1, pp. 37-50.

Grömping, M. and Sinpeng, A. (2018), “The 'Crowd-factor' in connective action: comparing protest communication styles of thai facebook pages", Journal of Information Technology and Politics, Vol. 15 No. 3, pp. 127-214.

Gruen, T.W., Osmonbekov, T. and Czaplewski, A.J. (2006), "eWOM: the impact of customer-to-customer online know-how exchange on customer value and loyalty", Journal of Business Research, Vol. 59 No. 4, pp. 449-456. 
Ha, L. (1996), "Advertising clutter in consumer magazines: dimensions and effects", Journal of Advertising Research, Vol. 36, pp. 76-84.

Ha, L. (2017), "Digital advertising clutter in an age of mobile media", in: Rodgers, S. and Thorson, E. (Eds), Digital Advertising: Theory and Research, Routledge, New York, NY, pp. 69-85.

Hair, J.F., Anderson, R.E., Tatham, R.L. and Black, W.C. (1998), Multivariate Analysis, Prentice Hall. Englewood Cliffs, NJ.

Hamilton, M., Kaltcheva, V.D. and Rohm, A.J. (2016), "Social media and value creation: the role of interaction satisfaction and interaction immersion", Journal of Interactive Marketing, Vol. 36, pp. 121-133.

Handley, L. (2017), "Half of all advertising dollars will be spent online by 2020, equaling all combined 'offline' ad spend globally”, available at: www.cnbc.com/2017/12/04/global-advertising-spend2020-online-and-offline-ad-spend-to-be-equal.html (accesed 10 November 2018).

Hofacker, C.F. and Belanche, D. (2016), "Eight social media challenges for marketing managers", Spanish Journal of Marketing-ESIC, Vol. 20 No. 2, pp.73-80.

Holbrook, M.B. (1986), "Aims, concepts, and methods for the representation of individual differences in esthetic responses to design features", Journal of Consumer Research, Vol. 13 No. 3, pp. 337-347.

Hsieh, J.K., Hsieh, Y.C. and Tang, Y.C. (2012), "Exploring the disseminating behaviors of eWOM marketing: persuasion in online video", Electronic Commerce Research, Vol. 12 No. 2, pp. 201-224.

Hussain, D. and Lasage, H. (2014), “Online video advertisement avoidance: can interactivity help?", Journal of Applied Business Research (JABR), Vol. 30 No. 1, pp. 43-50.

IAB (2018), "Estudio anueal de redes sociales 2018", available at: https://iabspain.es/wp-content/ uploads/estudio-redes-sociales-2018_vreducida.pdf (accessed 28 december 2018).

Jung, A.R. (2017), "The influence of perceived ad relevance on social media advertising: an empirical examination of a mediating role of privacy concern", Computers in Human Behavior, Vol. 70, pp. 303-309.

Kallas, P. (2018), “Top 15 most popular social networking sites and apps (August 2018)”, available at: www.dreamgrow.com/top-15-most-popular-social-networking-sites/ (accessed 28 November 2018).

Katz, E., Blumler, J.G. and Gurevitch, M. (1974), The Uses and Gratifications Approach to Mass Communication, Sage Publications, Beverly Hills, CA.

Kim, A.J. and Johnson, K.K. (2016), "Power of consumers using social media: examining the influences of brand-related user-generated content on facebook", Computers in Human Behavior, Vol. 58, pp. 98-108.

Kline, R.B. (2011), Principles and Practice of Structural Equation Modeling, 3rd ed, The Guildford Press, New York, NY.

Lang, A. (2000), "The limited capacity model of mediated message processing", Journal of Communication, Vol. 50 No. 1, pp. 46-70.

Lau-Gesk, L. and Meyers-Levy, J. (2009), "Emotional persuasion: when the valence versus the resource demands of emotions influence consumers' attitudes", Journal of Consumer Research, Vol. 36 No. 4, pp. 585-599.

Lebel, K. and Danylchuk, K. (2012), "How tweet it is: a gendered analysis of professional tennis players' self-presentation on twitter", International Journal of Sport Communication, Vol. 5 No. 4, pp. $461-480$.

Lee, Y.C. (2011), "Brand loyalty and post-adoption variations for the mobile data services: gender differences", Computers in Human Behavior, Vol. 27 No. 6, pp. 2364-2371.

Leibowitz, B. (2018), "Instagram vs Facebook: which can boost your business more?" available at: www.dreamgrow.com/instagram-facebook-advertising/ (accessed 22 November 2018). 
SJME

23,1

92

Li, H. and Lo, H.Y. (2015), "Do you recognize its Brand? The effectiveness of online in-stream video advertisements", Journal of Advertising, Vol. 44 No. 3, pp. 208-218.

Li, H., Edwards, S.M. and Lee, J.-H. (2002), "Measuring the intrusiveness of advertisements: scale development and validation", Journal of Advertising, Vol. 31 No. 2, pp. 37-47.

Lin, C.A. and Kim, T. (2016), "Predicting user response to sponsored advertising on social media via the technology acceptance model”, Computers in Human Behavior, Vol. 64, pp. 710-718.

Ljepava, N., Orr, R.R., Locke, S. and Ross, C. (2013), "Personality and social characteristics of facebook non-users and frequent users", Computers in Human Behavior, Vol. 29 No. 4, pp. 1602-1607.

Lombard, M. and Snyder-Duch, J. (2001), "Interactive advertising and presence: a framework", Journal of Interactive Advertising, Vol. 1 No. 2, pp. 56-65.

Lopez, M. and Sicilia, M. (2014), "eWOM as source of influence: the impact of participation in eWOM and perceived source trustworthiness on decision making", Journal of Interactive Advertising, Vol. 14 No. 2, pp. 86-97.

Lutz, R.J. (1985), "Affective and cognitive antecedents of attitude toward the ad: a conceptual framework" in Alwitt L.F. and Mitchell A. (Eds), Psychological Processes and Advertising Effects: Theory, Research and Applications, Erlbaum, Hillsdale, NJ, pp. 45-65.

Malhotra, N.K. (1982), "Information load and consumer decision making", Journal of Consumer Research, Vol. 8 No. 4, pp. 419-430.

Marcus, S.R. (2015), "Picturing ourselves into being: assessing identity, sociality and visuality on Instagram", in International Communication Association Conference, San Juan, Puerto Rico.

Marinucci, J. (2018), "Five social media trends that will impact digital advertising", available at: www. forbes.com/sites/forbesagencycouncil/2018/09/14/five-social-media-trends-that-will-impactdigital-advertising/\#26f4eebe2f05 (accessed 17 November 2018).

Meyers-Levy, J. and Maheswaran, D. (1991), "Exploring differences in males' and females' processing strategies", Journal of Consumer Research, Vol. 18 No. 1, pp. 63-70.

Muscanell, N.L. and Guadagno, R.E. (2012), "Make new friends or keep the old: gender and personality differences in social networking use", Computers in Human Behavior, Vol. 28 No. 1, pp. 107-112.

Myers, K.K. and Sadaghiani, K. (2010), "Millennials in the workplace: a communication perspective on millennials' organizational relationships and performance", Journal of Business and Psychology, Vol. 25 No. 2, pp. 225-238.

Nguyen, M.H., van Weert, J.C., Bol, N., Loos, E.F., Tytgat, K.M., van de Ven, A.W. and Smets, E.M. (2017), "Tailoring the mode of information presentation: effects on younger and older adults' attention and recall of online information", Human Communication Research, Vol. 43 No. 1, pp. 102-126.

Pashkevich, M., Dorai-Raj, S., Kellar, M. and Zigmond, D. (2012), "Empowering online advertisements by empowering viewers with the right to choose: the relative effectiveness of skippable video advertisements on YouTube", Journal of Advertising Research, Vol. 52 No. 4, pp. 451-457.

Pendergast, D. (2009), "Generational theory and home economics 1: future proofing the profession", Family and Consumer Sciences Research Journal, Vol. 37 No. 4, pp. 504-522.

Phillips, L.W. and Sternthal, B. (1977), "Age differences in information processing: a perspective on the aged consumer", Journal of Marketing Research, Vol. 14 No. 4, pp. 444-457.

Phua, J., Jin, S.V. and Kim, J.J. (2017), "Gratifications of using facebook, Twitter, Instagram, or snapchat to follow brands: the moderating effect of social comparison, trust, tie strength, and network homophily on brand identification, brand engagement, brand commitment, and membership intention", Telematics and Informatics, Vol. 34 No. 1, pp. 412-424.

Pikas, B. and Sorrentino, G. (2014), "The effectiveness of online advertising: consumer's perceptions of ads on facebook, Twitter and YouTube", Journal of Applied Business and Economics, Vol. 16 No. 4, pp. 70-81. 
Puccinelli, N., Goodstein, R.C., Grewal, D., Price, R., Raghubir, P. and Stewat, D. (2009), "Customer experience management in retailing: understanding the buying process", Journal of Retailing, Vol. 85 No. 1, pp. 15-30.

Ragowsky, A. and Awad, N.F. (2008), "Establishing trust in electronic commerce through online word of mouth: an examination across genders", Journal of Management Information Systems, Vol. 24 No. 4, pp. 101-121.

Rambe, P. and Retumetse, J.J. (2017), "Impact of social media advertising on high energy drink preferences and consumption", Journal of Applied Business Research (JABR), Vol. 33 No. 4, pp. 653-668.

Real, K., Mitnick, A.D. and Maloney, W.F. (2010), "More similar than different: millennials in the US building trades", Journal of Business and Psychology, Vol. 25 No. 2, pp. 303-313.

Redondo, I. and Aznar, G. (2018), "To use or not to use ad blockers? The roles of knowledge of ad blockers and attitude toward online advertising", Telematics and Informatics, Vol. 35 No. 6 , pp. 1607-1616.

Rodgers, S. and Thorson, E. (2017), Digital Advertising: Theory and Research, Taylor and Francis, New York, NY.

Rotfeld, J.H. (2006), "Understanding advertising clutter and the real solution to declining audience attention to mass media commercial messages", Journal of Consumer Marketing, Vol. 23 No. 4, pp. 180-181.

Sashittal, H.C., DeMar, M. and Jassawalla, A.R. (2016), "Building acquaintance brands via snapchat for the college student market”, Business Horizons, Vol. 59 No. 2, pp. 193-204.

Sheldon, P. (2008), "The relationship between unwillingness-to-communicate and students' facebook use", Journal of Media Psychology, Vol. 20 No. 2, pp. 67-75.

Sheldon, P. and Bryant, K. (2016), "Instagram: motives for its use and relationship to narcissism and contextual age", Computers in Human Behavior, Vol. 58, pp. 89-97.

Shi, S., Chen, Y. and Chow, W.S. (2016), "Key values driving continued interaction on brand pages in social media: an examination across genders", Computers in Human Behavior, Vol. 62, pp. 578-589.

Smith, K.T. (2011), "Digital marketing strategies that millennials find appealing, motivating, or just annoying", Journal of Strategic Marketing, Vol. 19 No. 6, pp. 489-499.

Smith, L. (2018), "How much do instagram ads cost? Plus 8 tips for saving money", available at: www. wordstream.com/blog/ws/2017/06/05/instagram-ads-cost (accessed 8 September 2018).

Soroka, A.J., Wright, P., Belt, S., Pham, D.T., Dimov, S.S., De Roure, D. and Petrie, H. (2006), "User choices for modalities of instructional information", in IEEE International Conference on Industrial Informatics in Singapore, IEEE, Singapore, Online, pp. 411-416.

Steenkamp, J.B. and Geyskens, I. (2006), "How country characteristics affect the perceived value of a Website", Journal of Marketing, Vol. 70 No. 3, pp. 136-150.

Sutherland, T. (2014), "Getting nowhere fast: a teleological conception of socio-technical acceleration", Time and Society, Vol. 23 No. 1, pp. 49-68.

Taken Smith, K. (2012), "Longitudinal study of digital marketing strategies targeting millennials", Journal of Consumer Marketing, Vol. 29 No. 2, pp. 86-92.

Tan, G.W.H., Lee, V.H., Hew, J.J., Ooi, K.B. and Wong, L.W. (2018), "The interactive mobile social media advertising: an imminent approach to advertise tourism products and services?", Telematics and Informatics, Vol. 35 No. 8, pp. 2270-2288.

Taylor, C.R. (2018), "Generational research and advertising to millennials", International Journal of Advertising, Vol. 37 No. 2, pp. 165-167.

Taylor, D.G., Lewin, J.E. and Strutton, D. (2011), "Friends, fans, and followers: do ads work on social networks? How gender and age shape receptivity", Journal of Advertising Research, Vol. 51 No. 1, pp. 258-275. 
SJME

23,1

Teo, T. (2016), "Do digital natives differ by computer self-efficacy and experience? An empirical study", Interactive Learning Environments, Vol. 24 No. 7, pp. 1725-1739.

Thelwall, M. (2008), "Social networks, gender, and friending: an analysis of MySpace member profiles", Journal of the American Society for Information Science and Technology, Vol. 59 No. 8, pp. 1321-1330.

Truong, Y. and Simmons, G. (2010), "Perceived intrusiveness in digital advertising: strategic marketing implications", Journal of Strategic Marketing, Vol. 18 No. 3, pp. 239-256.

Van Noort, G. and Willemsen, L. M. (2012), "Online damage control: the effects of proactive versus reactive webcare interventions in consumer-generated and brand-generated platforms", Journal of Interactive Marketing, Vol. 26 No. 3, pp. 131-140.

Vollmers, S. and Mizerski, R. (1994), "A review and investigation into the effectiveness of product placements in films", in Proceedings of the 1994 Conference of the American Academy of Advertising in 1994 American Academy of Advertising, Athens, GA pp. 97-102.

Voorveld, H.A., van Noort, G., Muntinga, D.G. and Bronner, F. (2018), "Engagement with social media and social media advertising: the differentiating role of platform type", Journal of Advertising, Vol. 47 No. 1, pp. 38-54.

Yadav, S.M., de Valck, K., Hennig-Thurau, T., Hoffman, L.D. and Spann, M. (2013), "Social commerce: a contingency framework for assessing marketing potential", Journal of Interactive Marketing, Vol. 27 No. 4, pp. 311-323.

Zhang, K.Z., Benyoucef, M. and Zhao, S.J. (2015), "Consumer participation and gender differences on companies' microblogs: a brand attachment process perspective", Computers in Human Behavior, Vol. 44, pp. 357-368.

Zhou, M., Lei, L., Wang, J., Fan, W. and Wang, A.G. (2014), "Social media adoption and corporate disclosure”, Journal of Information Systems, Vol. 29 No. 2, pp. 23-50.

Zhu, Z., Wang, J., Wang, X. and Wan, X. (2016), "Exploring factors of user's peer-influence behavior in social media on purchase intention: evidence from QQ", Computers in Human Behavior, Vol. 63, pp. 980-987.

\section{Further reading}

Knoll, J. (2016), "Advertising in social media: a review of empirical evidence", International Journal of Advertising, Vol. 35 No. 2, pp. 266-300.

Newberry, C. (2018), "Social media advertising 101: how to get the most out of your budget", available at: https://blog.hootsuite.com/social-media-advertising/ (accessed 28 November 2018).

\section{Corresponding author}

Daniel Belanche can be contacted at: belan@unizar.es

For instructions on how to order reprints of this article, please visit our website: 